\title{
REPRESENTACIONES SOCIALES SOBRE EDUCACIÓN ENTRE PRESOS COLOMBIANOS
}

\author{
Omar Alejandro Bravo \\ Diana Marcela Huertas
}

\section{Resumen}

La cárcel ha fracasado con relación a su propósito declarado de resocializar a los infractores a la ley. La educación en contextos carcelarios se aplica como un tratamiento más vinculado a esos fines de rehabilitación, lo que relega otros sentidos posibles derivados de esa experiencia. Esta investigación analizó las representaciones sociales sobre educación entre internos de una cárcel de Cali, Colombia. Las representaciones sociales encontradas se relacionaron con el sentido utilitario de la educación, como redimir pena, ocupar el tiempo o poder mejorar la relación con su familia y el resto de la sociedad una vez cumplida la pena, siendo éste un tipo de representación social atravesada por el discurso de la resocialización mencionado.

Palabras clave: representaciones sociales; cárcel; educación.

\section{REPRESENTAÇÕES SOCIAIS SOBRE EDUCAÇÃO ENTRE PRESOS COLOMBIANOS}

\section{Resumo}

A prisão tem fracassado em relação ao propósito declarado de ressocializar os infratores à lei. A educação nos contextos carcerários aplica-se como mais um tratamento vinculado a esses fins de reabilitação, o que relega outros sentidos possíveis derivados dessa experiência. Esta pesquisa analisou as representações sociais sobre educação, entre internos de uma prisão de Cali, Colômbia. As representações sociais encontradas, vinculam-se ao sentido utilitário da educação, como redimir a pena, ocupar o tempo ou poder estabelecer laços sociais mais consistentes e harmónicos com as famílias e o resto da sociedade uma vez cumprida a condena, sendo esse um tipo de representação social atravessada pelo discurso da ressocialização mencionado.

Palavras-chave: representações sociais; prisão; educação.

\section{SOCIAL REPRESENTATIONS ON EDUCATION AMONG COLOMBIAN PRISONERS}

\begin{abstract}
Prisions has been failing in relation to the purposes of resocialize people who have broken the law. Within this framework, prison education is applied as a treatment with rehabilitation purposes, which relegates other possible meanings. This research analyzed the social representations about education in prisioners of Cali, Colombia. The social representations found were related to the utilitarian meaning of education, such as redemption penalty, occupying time or establish stronger and warmer social ties with their families and the rest of society once the sentence was completed, being this one type of social representation crossed by the ideals of re-socialization.
\end{abstract}

Keywords: social representation, prison, education. 
DOI: $10.12957 /$ teias.2022.53180

\section{INTRODUCCIÓN}

En Colombia, el número de personas privadas de libertad asciende a 123.629, distribuidas en los diferentes centros penitenciarios del país (INPEC, 2019), lo que marca un porcentaje de hacinamiento del 53,65\%. Este contexto agrava los grandes problemas de salubridad, violencia y consumo de drogas, entre otros, propios de los sistemas penitenciarios latinoamericanos en general, signados por esta situación estructural que afecta principalmente a jóvenes en situación de exclusión (CARRANZA, 2018).

Los declarados propósitos de estos dispositivos de castigo, relacionados a la resocialización de los infractores a la ley, encuentran su límite también en estas condiciones estructurales, pues resulta complejo pensar en ideales "re" en contextos en los que la dignidad humana se ve vulnerada. Numerosas estrategias intentan dar soporte a dichos propósitos fallidos, entre ellas, la capacitación para el trabajo y la educación.

Sus limitaciones se vinculan a la imposibilidad de atender a una población tan amplia, a la escasa proyección que estas capacitaciones encuentran en el retorno a la vida social y a los imaginarios que las atraviesan, siempre signados por una representación del sujeto preso que lo supone como privado de características personales y relacionales que le impiden una integración social plena y respetuosa de la ley.

En el caso de la educación en particular, el sujeto preso se ve enfrentado a esta doble exigencia institucional y discusiva: aprender y que este aprendizaje contribuya a esa transformación moral.

Cabe confrontar esta expectativa con otras definiciones de educación y su sentido:

La educación, vista desde la mirada de la educación social, se constituye como un componente insoslayable de la construcción social y coproducción de subjetividad, ya que ella tramita el abordaje de conocimientos, distribuye el capital cultural, socializa y asocia saberes, incorpora actores, recuerda mitos, teje vínculos con lo desconocido, con el conocimiento, con los otros, con el mundo. La educación así entendida se hace un imperativo de inscripción, construcción de identidad, pertenencia y lazo en las sociedades humanas (SCARFÓ, 2005, p. 3).

Aunque esta noción de educación aparezca como más apropiada para los contextos carcelarios, la realidad es que la enseñanza en esos espacios se implementa con otros fines. Según autores como Scarfó (2005), Campos, Finucci (2009), Rangel (2013) y los principios definidos por la Unesco (1999), la resocialización, rehabilitación y reinserción se convierten en sinónimos de la palabra educación en escenarios carcelarios, quedando la segunda subordinada a los primeros.

Por esto, esos escenarios " [...] no llegan a concebirse como posibles espacios reeducativos porque, en realidad, cualquier propuesta de actividad tiende a considerarse en un orden de importancia secundario frente a la misma reclusión" (CANTERO, 2010, p. 55).

Como posible agravante, y de acuerdo con Unesco (1999), la idea de ofrecer educación de calidad a delincuentes genera indignación en la población, principalmente en sociedades donde el suministro y el acceso de la población general a la educación es limitado.

Por todo esto, resulta de interés preguntarse por el sentido que la educación tiene para las personas privadas de libertad. Para este propósito, se propone en este texto analizar las representaciones sociales de internos de la cárcel de Villahermosa, Cali, que hacen parte del área educativa de la institución. 


\section{Marco teórico}

\section{Origen y sentido de las cárceles}

Según el recorrido histórico hecho por Foucault (1975) en su texto Vigilar y castigar: nacimiento de las prisiones, las prácticas de encierro y castigo datan del siglo XVI, extendiéndose hasta la actualidad. No se propone aquí hacer un análisis de la historia de estos dispositivos en ese extenso período, sino apenas de señalar una fecha aproximada de inicio de esas prácticas, destacando un cambio significativo, producido en el siglo XVIII, que configuró la forma y sentido de los establecimientos carcelarios hasta la actualidad.

Según Becaria (2000), cuya obra titulada De los delitos y las penas resume los principios de ese cambio, la tortura practicada hasta entonces contra criminales se justificaba por varios motivos, entre ellos la purgación de la infamia y la confesión de delitos. Se pensaba que el dolor daba paso a la expulsión de una maldad intrínseca del preso. Los delitos eran entendidos como insulto o daño al soberano por lo cual se requería de una muestra de poder ante la sociedad para infundir terror en los demás hombres y así evitar futuros crímenes. En la nueva lógica punitiva que Becaria propone, las penas deberían ser cuantificadas de acuerdo a principios claros que permitiesen asimilar un tiempo de reclusión para cada delito, dirigiéndose ahora la pena a evitar la realización de nuevos delitos a través de la reinserción social del infractor y evitándose la tortura y la violencia física.

De esta forma, hoy en día, el objeto de la punición “[...] ya no es el cuerpo, es el alma... el corazón, el pensamiento, la voluntad, las disposiciones” (FOUCAULT, 2002, p. 24). Sin embargo, el castigo físico ha adquirido otras formas, pues prácticas como el racionamiento alimenticio, la privación sexual, el encierro en celdas, la insalubridad, el hacinamiento, las condiciones antihigiénicas, son apenas algunos de los actos a los que el cuerpo se ve sometido.

En este sistema de control, la cárcel busca:

Regular para el hombre el tiempo de vigilia y sueño, de la actividad y el reposo, el número y la duración de las comidas, la calidad y la ración de los alimentos, la índole y el producto del trabajo, el tiempo de oración, el uso de la palabra, y por decirlo así, hasta del pensamiento (FOUCAULT, 2002, p. 239).

En esta perspectiva moralizante, la idea del encierro como castigo parte de la base de que el individuo en soledad y privado de su libertad reflexiona y llega al arrepentimiento, modificando sus pensamientos y acciones, pues "[...] será en el aislamiento donde el remordimiento vendrá a asaltar al sujeto" (FOUCAULT, 2002, p. 240), suponiendo así que castigar implica corregir, reformar y curar. Por esto, la prisión ha sido desde el comienzo una "[...] empresa de modificación de los individuos" (FOUCAULT, 2002, p. 235). Este ideal recae en parte sobre la educación; cárcel y educación terminan siendo, para la institución e incluso para los reclusos, diferentes vías para un mismo propósito, la moralización del individuo.

Las instituciones que tienen como propósito encerrar a las personas para su cuidado y/o resocialización, son definidas por Goffman (2004, p. 13) como instituciones totales, caracterizadas por ser " [...] un lugar de residencia y trabajo, donde un gran número de individuos en igual situación, aislados de la sociedad por un periodo apreciable de tiempo, comparten en su encierro una rutina diaria, administrada formalmente".

En este contexto, al interno se le despoja de la cualidad de sujeto, algo que Goffman llamó la mutilación del yo. Compartir todos los ámbitos de la vida como dormir, trabajar, ir al baño, tener relaciones sexuales, ir al médico, estudiar y demás actividades, implica una "[...] ruptura con el 
DOI: $10.12957 /$ teias.2022.53180

ordenamiento social básico en la sociedad moderna" (GOFFMAN, 2004, p. 19) en la cual están inmersos, por ejemplo, los sujetos que llegan por primera vez a la cárcel.

Esta idea de mutilación que propone Goffman (2004) responde a imaginarios de resocialización que ven al recluso como un ser pasivo, sujeto a moldearse según el ideal de "deber ser" que tienen las instituciones y la sociedad en general. El recluso es catalogado como alguien malvado, que necesita cambiar, re-formarse, re-socializarse, re-insertarse según los principios institucionales, dejando de lado todo lo personal que constituye al individuo, pensamientos, deseos e ideales; se le despoja de su humanidad y pasa a ser visto únicamente como delincuente.

A pesar de sus efectos perjudiciales, de la evidente incompatibilidad entre propósitos y resultados, las cárceles continúan aumentando, en cantidad de establecimientos y en número de internos. En este sentido, según Foucault (2002, p. 234):

Conocidos son todos los inconvenientes de la prisión y que es peligrosa cuando no es inútil. Y sin embargo no se "ve" por qué remplazarla... la prisión parece traducir concretamente la idea de que la infracción ha lesionado, por encima de la víctima, a la sociedad entera, además es la forma más civilizada de las penas.

Estas instituciones deshumanizadoras y absorbentes producen también importantes afectaciones en la salud mental de los reclusos. Arroyo (2011, p. 13) señala cinco características, propias de los centros penitenciarios en países latinoamericanos, que de acuerdo a la Organización Mundial de la Salud (OMS), afectan la salud mental de los individuos que se encuentran en estos contextos, siendo éstas: "[...] el hacinamiento, las diferentes formas de violencia, la falta de privacidad, la falta de actividades significativas, y el aislamiento de redes sociales". De esta forma, el sujeto, al entrar en la prisión, deja detrás no solo el mundo exterior sino también su rol social, sus creencias, sus formas de relacionarse y de concebirse a sí mismo. Por esto, estas prácticas institucionales traen consigo "[...] una serie de depresiones, degradaciones, humillaciones y profanaciones del yo” (GOFFMAN, 2004, p. 27).

Son alarmantes las cifras que sustentan estos supuestos; en el caso de Colombia, alrededor del 68\% de la población reclusa presenta algún tipo de trastorno mental. De este porcentaje, el 23\% corresponde a depresión, el $22 \%$ a ansiedad, el $5 \%$ a psicosis y, el 54\%, a alcoholismo (FRASER, GATHERER, HAYTON, 2009). En este mismo orden, cabe destacar que los trastornos psiquiátricos en personas privadas de la libertad están presentes siete veces más que en el resto de la población, según la Oficina de Naciones Unidas contra Drogas y Delitos (UNODC, 2011). Para el caso de depresión y suicidios, Larrotta, Luzardo, Vargas, Rangel (2014) muestran que por cada suicidio fuera de la prisión, ocurren 17 dentro de estas.

Por esto, resulta necesario analizar esos dispositivos institucionales y sus efectos considerando, en este caso en particular, el papel de la educación en los mismos. Para este propósito, es pertinente considerar las representaciones sociales de las personas que transitan por esos espacios, lo que hace necesario también precisar algunos aspectos de esta teoría.

\section{REPRESENTACIONES SOCIALES}

Para Jodelet (1984, p. 472) las representaciones sociales son sistemas de referencias o imágenes que condensan un conjunto de significados más o menos estructurados o imprecisos de nociones, creencias, imágenes, metáforas y actitudes con los que los actores definen las situaciones y llevan a cabo sus planes de acción que "[...] permiten interpretar lo que nos sucede, categorías 
DOI: $10.12957 /$ teias.2022.53180

que sirven para clasificar las circunstancias, los fenómenos y a los individuos con quienes tenemos algo que ver".

En este marco teórico, las creencias del sentido común constituyen el espacio epistémico de las representaciones sociales y "[...] sirven para orientar la acción de los individuos, los grupos y las comunidades” (ÁLVAREZ BERMÚDEZ, 2002, p. 89).

El objeto de estudio de las representaciones sociales son los fenómenos de la ideología y la comunicación. Se define a la primera como "[...] los sistemas de representaciones y actitudes que forman la realidad social, y en la que se incluyen fenómenos como los de las creencias, los prejuicios sociales y raciales, estereotipos, etc." (ÁLVAREZ BERMÚDEZ, 2002, p. 84). Se concibe a la comunicación como "[...] los medios empleados, tanto lingüísticos como no-lingüísticos para transmitir información e influir en los demás” (ÁLVAREZ BERMÚDEZ, 2002, p. 85).

La parte social de las representaciones se "[...] desprende de un doble factor, ser elaboradas por un grupo y ser compartidas por el mismo" (RODRÍGUEZ, 2003, p. 60). Lo social deja de ser algo externo a la persona y pasa a ser tratado como algo que se encuentra en constante relación con el sujeto que lo constituye y es constituido a través de sus acciones (GONZÁLEZ REY, MORI, 2010).

Según Jodelet, lo social interviene de diversas maneras:

Por el contexto concreto en el cual están situadas personas y grupos, por la comunicación que se establece entre ellos, por los cuadros de aprehensión que les proporciona su bagaje cultural; por los códigos, valores e ideologías ligados a las posiciones o pertenencias sociales específicas (JODELET, 1984, p. 475).

Para explicar los procesos que intervienen en la construcción de una representación social, Moscovici (1961) señaló la existencia de dos mecanismos: la objetivación y el anclaje, los cuales "[...] explican cómo lo social transforma un conocimiento en representación y como esta representación transforma lo social” (RODRÍGUEZ, 2003, p. 57).

A través de su interacción social, los grupos van estableciendo nexos entre conceptos y objetos. Es así como se establece el proceso de objetivación que involucra 3 fases. La primera es la selección de la información que el contexto social ofrece sobre un objeto; en la segunda fase la información se asimila y se establecen características fijas del objeto, esto es, crear el denominado núcleo central propuesto por Abric (1993). A esas características fijas se van uniendo nuevos elementos secundarios que conformarían los elementos periféricos. En la tercera y última fase “[...] esa información asimilada se integra de nuevo al medio a través de su actividad cotidiana, ya cargada con esa lógica representacional de sentido común" (ÁLVAREZ BERMÚDEZ, 2002, p. 82).

El segundo mecanismo, el anclaje, consiste en "[...] integrar la información de un objeto dentro del sistema de pensamiento ya constituido para darle sentido a los objetos nuevos, desconocidos que aparecen en el campo social” (ÁLVAREZ BERMÚDEZ, 2002, p. 91).

De esta manera, las representaciones sociales tienen tres funciones básicas: “[...] la función de la integración cognoscitiva de lo novedoso al sistema de pensamiento ya constituido; la función de la interpretación de la realidad, y la función de la orientación del comportamiento y las relaciones sociales" (ÁLVAREZ BERMÚDEZ, 2002, p. 91).

Desde estas coordenadas teóricas, resulta de interés entender las representaciones sociales de los sujetos privados de libertad en torno el sentido de la educación en la cárcel considerando, como ya fue mencionado, que estas prácticas mantienen una relación de proximidad y al mismo tiempo de tensión con los propósitos resocializadores de estas instituciones. Para este fin, se tomó como objeto de este análisis el espacio educativo de la cárcel de Villahermosa, Cali. 


\section{CONTEXTO DE LA INVESTIGACIÓN Y METODOLOGÍA}

Villahermosa es un establecimiento penitenciario de mediana seguridad ubicado en la ciudad de Cali, construido en 1958 inicialmente con capacidad para albergar 900 internos (INPEC, 2019). Para el año 2015, la cárcel contaba con 6.574 reclusos, sobrepasando en alarmantes cantidades su capacidad (HINCAPIÉ, 2014). Este centro de reclusión está dividido en 11 patios, entre los que se encuentran subdivisiones como la del sector que ocupa la comunidad LGBTI. La policía traslada a diario unos 10 reclusos, es decir, un promedio de 3.360 anualmente. Por esto, por ejemplo, el patio 1A tiene 1.011 internos y su capacidad es para 126; lo mismo pasa con el patio 2, que en condiciones dignas podría albergar a 186 reclusos y estaba habitado, hasta el 2015, por 999 personas (HINCAPIE, 2014).

Ante la imposible tarea de controlar a esta población con los escasos recursos humanos y técnicos de la propia institución, cada patio cuenta con un líder quien, entre otras cosas, se ocupa de vigilar y mantener el orden, lo que agrega una forma más de control y disciplina a las que la propia cárcel posee.

El área educativa de la cárcel se encuentra en la parte posterior del predio. Dispone de un espacio reducido, coordinado por personas que no suelen tener capacitación en docencia o pedagogía y que se ocupan de organizar las rutinas de entrada y salida de los internos que estudian allí y del personal docente. Cuentan para este fin con el apoyo de monitores elegidos entre los propios internos que trabajan en este apoyo operativo, recibiendo por esto un descuento en la pena.

Considerando la facilidad de acceso a este grupo, hicieron parte de esta investigación 17 monitores del área educativa. Se trabajó con la metodología del completamiento de frases, teniendo en cuenta también la imposibilidad de grabar entrevistas, y se utilizaron consentimientos informados, para garantizar los aspectos éticos necesarios al trabajo con esta población.

En relación a esta metodología utilizada, González Rey (2010) afirma que el ejercicio de completar frases es un instrumento compuesto por una cantidad de frases inconclusas, que deben ser completadas por el participante. Esta metodología es de carácter cualitativo, y propone reunir información en torno a un tema y objetivos de una manera amplia y flexible, lo que permite que las representaciones sociales de las personas participantes se manifiesten.

Se utilizaron cuatro frases incompletas: 1) Hago parte del área educativa de la cárcel porque... 2) La educación para mí significa... 3) La educación me sirve para... 4) Gracias a la educación podría lograr...

\section{Análisis de la información}

Considerando la información producida, se desarrollaron aquí dos categorías de análisis. La primera tiene que ver con la motivación y el sentido que los internos le otorgan a su pertenencia al espacio educativo de la cárcel. En la segunda categoría de análisis se consideran las perspectivas de futuro que los monitores proyectan a partir de esta experiencia educativa y el lazo social vinculado.

\section{Motivaciones y sentido de la educación}

Entre aquello que mueve a los internos a participar del espacio educativo ofrecido en la cárcel de Villahermosa se puede identificar el descuento en la pena por trabajar como monitores en el área educativa de la cárcel, como uno de los motivos principales.

A este respecto, la Resolución 6541 de 1995 en el capítulo titulado 'Reglamentación del estudio y la enseñanza en los establecimientos carcelarios y de la manera como los mismos pueden 
DOI: $10.12957 /$ teias.2022.53180

servir para la redención de pena”, en el artículo donde se describen las actividades de enseñanza válidas para la redención de pena se afirma que:

A los detenidos y condenados se les computará, por cada cuatro horas de enseñanza, un día de estudio. Se computará como un día de enseñanza la dedicación a esta actividad durante cuatro horas continuas o discontinuas, En ningún caso se podrán computar más de cuatro horas diarias de enseñanza. No se programarán más de veinte horas semanales de enseñanza para cada interno ni más de ochocientas horas en el año y, en todo caso, este será el límite de horas de enseñanza computables en este período para redención de pena (RESOLUCIÓN 6541, 1995).

En este sentido, de los 17 participantes, 15 mencionaron la redención de pena como la principal motivación para pertenecer al grupo de monitores académicos de la cárcel. Esto se expresa en frases como:

Hago parte del área educativa de la cárcel porque es la mejor opción que yo tengo para redimir mi tiempo (Sujeto 3).

Hago parte del área educativa de la cárcel porque primeramente y francamente por el deseo de redimir tiempo para poder tener una nueva oportunidad ante la sociedad... (Sujeto 12).

Hago parte del área educativa porque me ayuda a estar tranquilo, me distraigo, rebajo tiempo de mi pena por el descuento, colaboro y paso el tiempo lo mejor que puedo ayudándole a los demás a aprender algo, en mi caso sistemas (Sujeto 9).

Otra de las motivaciones que manifestaron reiterativamente los internos en el completamiento de frases fue la posibilidad de mantenerse ocupados, estar en un espacio diferente al de la celda y los patios hacinados, mencionando que el abismal contraste entre un espacio y otros representa para ellos tranquilidad, como se percibe en la cita anterior.

También fue reiterativa la motivación que genera aprovechar y hacer algo útil con todo el tiempo libre en la cárcel, pues el tiempo que se pasa en dicha institución es percibido como perdido, en la medida en que su vida social, familiar y cultural se encuentra en una pausa para ellos, y se sienten seres improductivos.

Este tipo de motivaciones se aleja de propósitos relacionados a la educación en sí, al menos en su aspecto crítico y liberador; esto resulta entendible dado que "[...] se ha repetido hasta la saciedad que es una paradoja pretender educar para la libertad en condiciones de ausencia de libertad" (MIR PUIG, 1990, p. 113).

Por otra parte, aparece el deseo de colaborar con los procesos educativos que desarrollan los otros internos. Ayudar a enseñar a quienes no tuvieron la oportunidad de estudiar la primaria o secundaria se convierte en una forma significativa de invertir su tiempo, les hace sentirse útiles, agentes de cambio y de cierta manera se convierte en un mecanismo de "hacer el bien", como ellos lo mencionan, en medio de tanta desigualdad e injusticia. En este sentido, manifiestan:

Hago parte del área educativa de la cárcel porque me gusta enseñar y aportar elementos de mi experiencia a los demás para apoyarlos y ayudarlos en sus proyectos de vida (Sujeto 6).

Hago parte del área educativa de la cárcel porque en este espacio puedo aprovechar el tiempo enseñando como monitor y haciendo algo por esta sociedad a la que le debo tanto (Sujeto 2). 
DOI: $10.12957 /$ teias.2022.53180

Comentan también, reiterativamente, la intención de "ser ejemplo para la sociedad" (Sujeto 15), "aportar a la sociedad" (Sujeto 4) y "reinsertarme en la escala social” (Sujeto 13).

Este tipo de expresiones mencionada contrasta parcialmente con otras, que destacan el sentido de la educación de una forma abstracta, sin relacionarse claramente con la experiencia específica por la que están atravesando.

La educación para mí significa todo lo que me ayuda ser persona y me ubica en la escala de la sociedad como persona (Sujeto 6).

La educación para mí es algo muy importante porque es la raíz de todo nuestro ser y por medio de ella es que nos formamos como personas (Sujeto 3).

\section{EDUCACIÓN, FUTURO Y LAZO SOCIAL}

En lo que hace a sus perspectivas de futuro, un motivo compartido por la mayoría de los internos participantes en la investigación tuvo que ver con su posible resocialización. Es curioso como ninguno ahonda en lo que esta palabra significa para ellos, solo enuncian frases como:

Hago parte de este espacio porque me ayuda a resocializarme y convertirme en alguien que puede ser parte de la sociedad (Sujeto 17).

La educación para mí significa la oportunidad de resocializarme y reinsertarme en la sociedad (Sujeto 12).

Hago parte del área educativa de la cárcel porque siento que contribuyo a mi resocialización al mismo tiempo que lo hago con la de los estudiantes a mi cargo (Sujeto 5).

Esta noción de resocialización es algo que mueve al sujeto privado de su libertad, pero es una idea apropiada de voces ajenas que ha instaurado sus propios significados en torno a la educación en contextos carcelarios, mostrando el atravesamiento de las expectativas institucionales, en una polifonía bakthiniana, donde otras voces resuenan en un discurso (BAKTHIN, 2011).

Estas expectativas anteriormente indicadas en relación a la educación, se extienden también, en algunos casos, al vínculo con la familia:

La educación para mí significa que puedo demostrarle a mi hijo que su papá puede ser alguien en la vida (Sujeto 16).

La educación para mí es una herramienta para poder educar adecuadamente a mis hijos (Sujeto 1).

La educación es lo que me permite ser un ejemplo para mis hijos y mostrarle a $\mathrm{mi}$ familia que puedo salir adelante (Sujeto 17).

La familia es el principal vínculo que el recluso tiene con el exterior, es el puente entre él y la sociedad y "[...] el hecho de que sus familias se mantengan fuera de la institución suele permitir que los internos permanezcan integrados en la comunidad exterior y se sustraigan así a la tendencia absorbente de la institución total" (GOFFMAN, 2004, p. 25).

Esta forma de vínculo y la proyección imaginaria que del mismo se realiza, es una manera de enfrentar lo que Foucault (2002) denominó como individualización coercitiva, donde el sujeto es apartado de sus relaciones sociales previas a la reclusión, y al perder el vínculo y la pertenencia a un grupo social queda sumergido en un sistema opresivo de poder.

Algunos internos relacionan también la educación con una posible contribución a una sociedad más justa y a un mejor nivel de vida futuro, proyecciones éstas siempre descontextualizadas de la experiencia concreta, como ya fue mencionado: 
DOI: $10.12957 /$ teias.2022.53180

La educación me sirve para tener un mejor desarrollo como persona ante la sociedad, como lo dije anteriormente la educación es la base de la sociedad, de un país, es primordial que la gente se eduque, con esto miraremos una sociedad sin hambre, sin violencia, obtendremos menos delincuencia, nuestros niños serán personas de bien, habrá honestidad y responsabilidad para llevar las riendas de un país (Sujeto 12).

La educación me sirve para comprender mejor mi entorno, aceptar otras verdades desde diferentes puntos de vista, tolerar diferencias. Sirve para aportar a la reconstrucción social partiendo de la transformación individual (Sujeto 7).

La educación me sirve para desarrollar conocimientos académicos para abrir puertas laborales las cuales también abren puertas sociales y económicas (Sujeto 4).

Gracias a la educación podría lograr mis metas y los objetivos que me propongo, lo aprendido bien aplicado es importante porque con un buen engranaje logro lo que me propongo. Tanto familiar, social y económicamente (Sujeto 8).

Gracias a la educación podría lograr que la sociedad me vea de una forma diferente, no sentirme rechazado ni excluido por haber estado en la cárcel y valoren mi labor aquí compartiendo mis conocimientos y ayudando a formar personas de bien (Sujeto 2).

La cuestión de la exclusión social, principalmente en su relación con los contenidos educativos y su proyección, dificultada por la condición de ex-preso y el estigma que eso acarrea, no se incluye en estas expresiones. De acuerdo con Scarfó (2003), la experiencia educativa debe efectuarse como un derecho humano, y debe estar dirigida a que "[...] el alumno-detenido pueda reconocerse como partícipe de una sociedad que en un momento lo excluye y que ahora, a partir de la oportunidad educativa que brinda la escuela, intente reintegrarse críticamente a ella" (SCARFÓ, 2003, p. 18). Esto supone que no alcanza con el esfuerzo individual del sujeto; es necesario también que la propia sociedad y el estado ofrezcan condiciones para que ese proceso alcance sus fines.

\section{DISCUSIÓN}

Las representaciones sociales expresadas en los discursos analizados permiten visualizar la situación oprobiosa que sufren las personas privadas de libertad en estos contextos. Se mezclan aquí representaciones que expresan un propósito más utilitario, como el descuento en la pena o la posibilidad de ocupar el tiempo libre permaneciendo en el área educativa, con otras que destacan el papel de la educación en general y su posible utilidad y proyección, tanto laboral como social y familiar, una vez retornado el sujeto a la vida civil y cumplida su pena.

Estas últimas representaciones se aproximan al discurso institucional de la resocialización, como ya fue mencionado. La necesidad de ser visto de forma diferente por la sociedad y la familia se enmarca en ese antes y después que esas políticas sostienen, donde el momento posterior debe reflejar una transformación moral.

De esta manera, el posible carácter crítico y transformador de la educación se diluye en esas expectativas. La educación bancaria, que Freire (1971) criticó en tanto se basa en la mera transmisión de conocimientos, se reproduce aquí con el agregado de los contenidos morales implicados. La educación entonces debe transformar al sujeto de acuerdo a ese designio institucional, aproximándose de alguna manera al tratamiento moral que Pinel (1801/2007) dispuso en los nacientes manicomios. Lo anterior aparece como contrapunto del tipo de educación que 
propone Scarfó (2003), como se mencionó anteriormente, como un escenario de coproducción de subjetividad, entendida como algo que se hace en conjunto y no en una sola vía, rescatando lo propio del otro, se construye en conjunto, y no en respuesta a uno ideales sociales o institucionales que se deben cumplir.

La función de monitor dota a esas representaciones sociales de una mayor potencia, ya que se trata aquí de cumplir con esos designios y velar por que otros también lo hagan. De hecho, en la interacción con algunos de los monitores participantes de esta investigación, se percibió la manera en que algunos de ellos hablaban en nombre de la institución, defendiendo su sentido y funcionamiento, fenómeno éste que es común en las instituciones totales.

\section{CONCLUSIONES}

Por todo esto, es necesario plantearse otros modelos educativos, específicos a la situación que se vive en las prisiones y las formas de socialización que aquí se producen. Estos modelos deben tener un carácter necesariamente crítico, en donde la trayectoria individual y social de cada sujeto pueda ser incluida, de manera también que dicha historia de vida contribuya en la discusión del propio sentido de la educación en los contextos carcelarios. De otra forma, probablemente todas estas representaciones sociales solo se sostendrán hasta la salida del sujeto de la prisión, ya que una vez que el mismo se reintegre a las mismas condiciones de vida anteriores a la pena (o peores, dado el efecto social del encarcelamiento), todos estos designios morales perderán también su sentido.

De alguna manera, esta perspectiva de una educación de carácter crítico, podría aproximarse a la de salud mental, entendiendo a esta última como relacionada a las condiciones concretas de existencia del sujeto y su capacidad y disposición de comprenderlas y modificarlas.

También desde esta posible aproximación, puede plantearse la noción de integración comunitaria, como superadora de los discursos "re" ya mencionados, dado que la misma supone un doble movimiento: del sujeto hacia la comunidad y de la comunidad hacia el sujeto, de forma de "[...] posibilitar al individuo una participación plena en los intercambios sociales y simbólicos" (GALENDE, 1997, p. 31).

Se trata, en definitiva, de entender a la cárcel, sus prácticas (la educación, entre ellas) y sus consecuencias como un fenómeno social complejo que muestra relaciones de exclusión social reparables a través de la construcción de una sociedad más justa, y no por medio de dispositivos moralizantes como el aquí considerado.

\section{REFERENCIAS}

ÁLVAREZ BERMÚDEZ, Javier. Estudio de las creencias, salud y enfermedad. México: Trillas, 2002, p. 261.

ABRIC, Jean Central system, peripheral system: Their functions and roles in the dynamics of social representation. Papers on social representations, 2 (2), p. 75-78, 1993.

ARROYO, Juan. Estrategias asistenciales de los problemas de salud mental en el medio penitenciario, el caso español en el contexto europeo. Revista Española de Sanidad Penitenciaria. España, 2011, 13. p. 100-111.

BAKTHIN, Mikhail. Las fronteras del discurso. Buenos Aires: Las cuarenta, 2011.

BECCARIA, Cesare. De los delitos y las penas. Temis, Bogotá, 2000 (Versión original, 1756). 
CAMPOS, Natalia; FINUCCI, Matías. Proyecto de formación docente. Educación en la cárcel: por la universalización del acceso a la educación. Entre Ríos: AGMER C. D. C., 2009.

CARRANZA, Elías. Introducción. En: BRAVO, Omar (ed.) Perspectivas multidisciplinarias sobre las cárceles. Una aproximación desde Colombia y América Latina. Cali: Icesi, 2018.

CARRASCO JIMÉNEZ, Edison. El pensamiento penal de Michael Foucault. Polis: Revista de la Universidad Bolivariana. 18, p. 1-16, 2007.

CANTERO, Fernando Gil. La acción pedagógica en las prisiones. Posibilidades y límites. Revista española de Pedagogía. n. 245. enero-abril, 2010. p. 49-64.

FOUCAULT, Michel. Vigilar y castigar. Nacimiento de la prisión. Buenos Aires: Siglo Veintiuno ediciones, 1975.

FOUCAULT, Michel. Vigilar y castigar. Nacimiento de la prisión. Buenos Aires: Siglo Veintiuno ediciones, 2002.

FRASER, Andrew; GATHERER, Alex; HAYTON, Paul. Mental health in prisons: great difficulties but are there opportunities. Public Health, Reino Unido, 2009, 123, p. 410-414.

FREIRE, Paulo. Pedagogía del oprimido. México: Siglo XXI, 1971, p. 116.

GALENDE, Emiliano. De un horizonte incierto: psicoanálisis y salud mental en la sociedad actual. Buenos Aires: Paidós, 1997.

GOFFMAN, Erving. Internados: ensayos sobre la situación social de los enfermos mentales. Buenos Aires: Amorrortu editores, 2004.

GONZALEZ REY, Fernando; MORI, Valeria. Las representaciones sociales como proceso subjetivo: un estudio de caso de hipertensión. CS n. 5. p. 221-240. Cali, Colombia, 2010.

GONZALEZ REY, Fernando. Personalidade saúde e modo de vida. São Paulo: Thomson Learning, 2004.

HINCAPIÉ, Laura. Así se sobrevive en Villahermosa, la cárcel más hacinada de Colombia. El País. 2014. Recuperado de http://www.elpais.com.co/judicial/asi-se-sobrevive-en-villahermosa-lacarcel-mas-hacinada-de-colombia.html.

INPEC. Informe estadístico enero 2018. Bogotá, D.C: Oficina asesora de planeación - Grupo estadística, 2019.

JODELET, Denise. La representación social: fenómeno, concepto y teoría. In: MOSCOVICI, Serge (ed.). Psicologia social, II. Buenos Aires: Paidós, 1984.

LARROTA, Richard Castillo; LUZARDO, Marianela Bruceño; VARGAS, Sandra Cifuentes; RANGEL, Kelly Noriega. Características del comportamiento suicida en cárceles de Colombia. Revista Criminalidad. v. 56, n. 1, 2014, p. 83-95.

RESOLUCIÓN 6541 DE 1995 (julio 28). Por medio de la cual se aclara y modifica la Resolución número 3272 del 26 de mayo de 1995. Recuperado de http://www.suinjuriscol.gov.co/viewDocument.asp?id=1831796.

MIR PUIG, Santiago. ¿Qué queda en pie de la resocialización? Eguzkilore: Cuaderno del Instituto Vasco de Criminología. n. extra 2, 1989, julio 1990.

MOSCOVICI, Serge. La Psychoanalyse, son image et son public. Paris: Presses Universitaires de France, 1961.

OFICINA DE LAS NACIONES UNIDAS CONTRA LA DROGA Y EL DELITO. Manual sobre reclusos con necesidades especiales. Panamá, 2011, p. 9-39. 
DOI: $10.12957 /$ teias.2022.53180

PINEL, Phillipe. Tratado médico-filosófico sobre a alienação mental. Porto Alegre: UFRGS, 2007 (originalmente publicado em 1801).

RANGEL, Hugo. Educación contra Corriente en las Cárceles Latinoamericanas: la enseñanza vs el castigo. In: Educação \& Realidade. Porto Alegre, v. 38, n. 1, p. 15-32, jan./mar. 2013. Recuperado de http://www.ufrgs.br/edu_realidade.

RODRIGUEZ, Tania. El debate de las representaciones sociales en la psicología social. Relaciones. Estudios de historia y sociedad, v. XXIV, n. 93, 2003.

SCARFÓ, Francisco. El derecho a la educación en las cárceles como garantía de una Educación en Derechos Humanos. Revista del Instituto Interamericano de Derechos Humanos, n. 36, San José, Costa Rica, julio-diciembre, 2003.

SCARFÓ, Francisco. Competencias del rol profesional pedagógico en la formación de docentes para la educación básica en cárceles. La Plata, inédito, 2005.

UNESCO. Educación de adultos y reclusos. Quinta Conferencia Internacional de Educación de las Personas Adultas. Hamburg: Druckerei Seeman, p. 1-14, 1999.

Submetido em março 2021

Aprovado em fevereiro 2022

\section{Informações do/a autor/a}

Omar Alejandro Bravo

Universidad Icesi, Director Maestría en Intervención Psicosocial. Cali, Colombia.

E-mail: oabravo@icesi.edu.co

ORCID: https://orcid.org/0000-0002-6184-9193

Diana Marcela Huertas

Psicóloga, Universidad Icesi. Diplomado Desarrollo psicológico en niños: aportes para la intervención. Universidad Javeriana, Cali. Colombia.

E-mail: dianahuertas05@hotmail.com

ORCID: https://orcid.org/0000-0001-6350-7843 